\title{
Spectroscopic Imaging of Bladder Cancer
}

\author{
S.G. Demos, R. Gandour-Edwards, R. Ramsamooj,
} R. deVere White

This article was submitted to Society of Photo-Optical Instrumentation Engineers Conference San Jose, CA, January 25-31, 2003

\section{January 1, 2003}

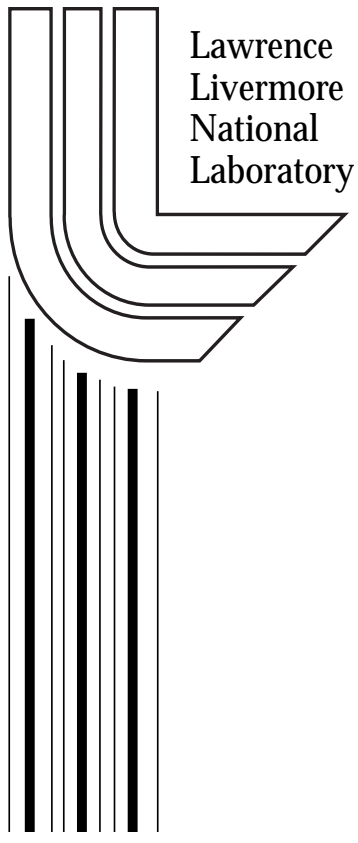




\section{DISCLAIMER}

This document was prepared as an account of work sponsored by an agency of the United States Government. Neither the United States Government nor the University of California nor any of their employees, makes any warranty, express or implied, or assumes any legal liability or responsibility for the accuracy, completeness, or usefulness of any information, apparatus, product, or process disclosed, or represents that its use would not infringe privately owned rights. Reference herein to any specific commercial product, process, or service by trade name, trademark, manufacturer, or otherwise, does not necessarily constitute or imply its endorsement, recommendation, or favoring by the United States Government or the University of California. The views and opinions of authors expressed herein do not necessarily state or reflect those of the United States Government or the University of California, and shall not be used for advertising or product endorsement purposes.

This is a preprint of a paper intended for publication in a journal or proceedings. Since changes may be made before publication, this preprint is made available with the understanding that it will not be cited or reproduced without the permission of the author.

This report has been reproduced directly from the best available copy.

Available electronically at http://www.doc.gov/bridge

Available for a processing fee to U.S. Department of Energy

And its contractors in paper from

U.S. Department of Energy

Office of Scientific and Technical Information

P.O. Box 62

Oak Ridge, TN 37831-0062

Telephone: (865) 576-8401

Facsimile: (865) 576-5728

E-mail: reports@adonis.osti.gov

Available for the sale to the public from

U.S. Department of Commerce

National Technical Information Service

5285 Port Royal Road

Springfield, VA 22161

Telephone: (800) 553-6847

Facsimile: (703) 605-6900

E-mail: orders@ntis.fedworld.gov

Online ordering: http://www.ntis.gov/ordering.htm

OR

Lawrence Livermore National Laboratory

Technical Information Department's Digital Library

http://www.llnl.gov/tid/Library.html 


\title{
Spectroscopic imaging of bladder cancer
}

\author{
Stavros G. Demos ${ }^{*}$ ab , Regina Gandour-Edwards ${ }^{\mathrm{b}}$, Rajen Ramsamooj ${ }^{\mathrm{b}}$, Ralph deVere White ${ }^{\mathrm{b}}$ \\ ${ }^{a}$ Lawrence Livermore National Laboratory, PO Box 808, L-411, Livermore, CA 94551. \\ ${ }^{\mathrm{b}} \mathrm{UC}$ Davis Medical School, 4501 X Street, Sacramento, CA 95817
}

\begin{abstract}
The feasibility of developing bladder cancer detection methods using intrinsic tissue optical properties is the focus of this investigation. In vitro experiments have been performed using polarized elastic light scattering in combination with tissue autofluorescence in the NIR spectral region under laser excitation in the green and red spectral regions. The experimental results obtained from a set of tissue specimens from 25 patients reveal the presence of optical fingerprint characteristics suitable for cancer detection with high contrast and accuracy. These photonic methods are compatible with existing endoscopic imaging modalities which make them suitable for in-vivo application.
\end{abstract}

Keywords: Tissue Imaging, Backscattering, Polarization, Tissue autofluorescence

\section{INTRODUCTION}

The utilization of optical instrumentation for medical applications is very wide and it is continuously expanding. Various endoscopic tools are currently utilized as diagnostic and interventional therapy guidance tools. Momentous developments that took place over the last three decades in laser technologies, optical imaging systems and compact personal computers have opened a window of opportunity to introduce novel photonic methods for the detection and treatment of disease. Various methods to detect and diagnose disease in real time are under consideration [1-7]. These methods are based on the detection of disease specific optical signatures originating in tissue structures and endogenous or exogenous chromophores. The advantages from the development of medical modalities that could provide sensitive and accurate real-time diagnosis would be tremendous.

The feasibility of developing surface or near surface cancer detection methods in the bladder using photonic technologies is the focus of this investigation. Two main imaging approaches are explored: a) NIR polarized elastic light scattering and b) tissue autofluorescence in the NIR spectral region under laser excitation in the green and red spectral regions.

\section{EXPERIMENTAL ARRANGEMENT}

The experiments were carried out using a compact spectroscopic imaging instrument that is located near the pathology room of the UC Davis Medical Center Hospital. In-vitro measurements of bladder tissue specimens obtained by transurethral resection or following cystectomy were performed immediately after surgical removal from the body followed by fixation of the sample for histo-pathology assessment. Figure 1 shows the schematic layout of the key optical components of this imaging system. The images are captured using a 35-mm camera lens and a liquid nitrogen cooled CCD camera. Two imaging methods were used based on a) polarization-sensitive light scattering under near infrared polarized illumination and, b) tissue autofluorescence in the 700-1000 $\mathrm{nm}$ using laser excitation in the green (532-nm) and the red $(632.8-\mathrm{nm})$.

To perform the light scattering imaging experiments, a white light source coupled to a fiber bundle is used to provide a nearly uniform illumination of the sample. A polarizer is positioned at the output of this fiber with its polarization orientation perpendicular to that of a second polarizer that is located in front of the camera lens. In this way, we record only the perpendicular polarization image component under illumination of the sample with 700-nm, 850-nm, and 1000$\mathrm{nm}$. The wavelength selection is achieved using $40-\mathrm{nm}$ bandwidth interference filters positioned on a filter wheel located at the output of fiber bundle. For the autofluorescence imaging experiments, the photoexcitation is provided by a 632.8$\mathrm{nm}$ He-Ne lacer and hy a 537-nm dinde-numned lacer The lacer lioht is trancferred into the imaoino rnmnartment of the * Demos1@llnl.gov; phone 925423 3388; fax 9254232463

ple. A narrow bana interrerence filter was positıoned in tront or tne output or tne fiber to ensure monocnromatic 111umination. 
The spectroscopic images of the specimens obtained using the system described above are subsequently compared with the histopathology map of the specimen. This study represents measurements of bladder specimens from 25 cancer patients for which pathology (performed after the completion of the experiment from each patient) showed that normal and cancerous tissue components existed in the specimen(s) studied from each patient. This allowed comparison of the optical properties of normal and cancer tissue as manifested in the optical images. Most samples were small in size (5$\mathrm{mm}$ in diameter or less) as they were obtained by transurethral resection. These small specimens were compressed between glass slides to a uniform thickness of approximately 1-mm. Following the acquisition of optical spectroscopic images as discussed in the previous section, all tissue specimens were processed for pathological assessment using standard hospital procedures. Usually a number of specimens or part of a single specimen were normal. Samples obtained from cystectomy were larger, typically having lateral dimensions of 3 to $4-\mathrm{cm}$ and thickness of approximately 5$\mathrm{mm}$. These samples were obtained from cross sectioning parts of the bladder containing normal and tumor tissue.

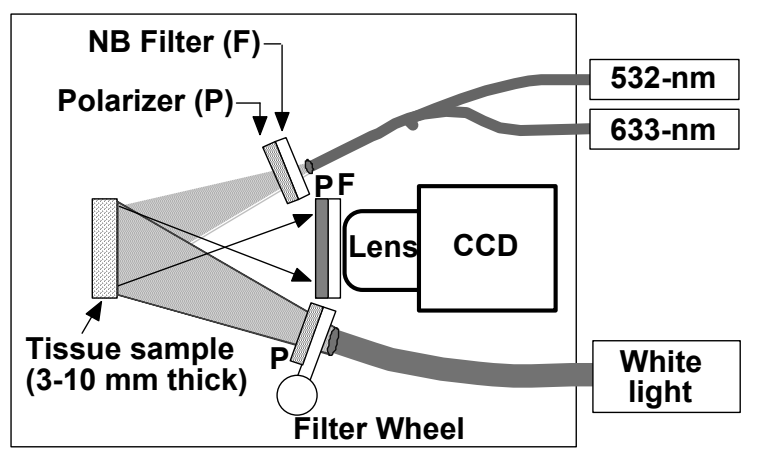

Figure 1: Schematic layout of the key optical components of this system

\section{EXPERIMENTAL RESULTS}

Typical experimental results from a specimen obtained from a patient that had undergone cystectomy are shown in figure 2. Figure 2a shows the cross-polarized light scattering image of the sample under 700-nm polarized illumination. Figures $2 \mathrm{~b}$ and $2 \mathrm{c}$ show the autofluorescence images in the 700-1000-nm spectral region under 532-nm and 633-nm laser excitation, respectively. The cancer lesion is located in the lower left part of the image and is clearly visible in all cases as a feature with lower image intensity than the normal tissue. In the 700-nm cross-polarized light scattering image the intensity of the cancer lesion is lower by a factor of $\approx 0.22$ compared to that of the normal tissue. The change in intensity between normal and cancer tissue is further enhanced in the autofluorescence images. More specifically, the intensity of the cancer lesion is lower by a factor of $\approx 0.63$ and $\approx 0.33$ in the NIR autofluorescence images obtained under $532-\mathrm{nm}$ and 633-nm, respectively. Inter-image operations can further enhance the visibility of the cancer lesion and better delineate the tumor's margins. Figure 2d shows the ratio image following division of the NIR autofluorescence image obtained under 633-nm excitation over that obtained under 532-nm excitation. In this case, the average digitized intensity from the part of the image that contained the tumor is higher by a factor of $\approx 0.8$ compared to that arising from normal tissue. In addition, in the ratio image obtained from division of the 700-nm cross-polarized light scattering image by the NIR autofluorescence image under 532 -nm excitation shown in figure $2 \mathrm{~d}$, the tumor has higher intensity by a factor of $\approx 1.1$ compared to normal tissue from the same patient.

Figure 3 shows a second example from tissue specimens that were obtained by transurethral resection from the same patient. This image shows the NIR autofluorescence image under $632.8 \mathrm{~nm}$ excitation from $8 \mathrm{small}$ (5-mm in diameter or less) bladder samples. These samples were compressed between glass slides to a uniform thickness of approximately 1$\mathrm{mm}$. In this image, the two specimens that exhibit higher intensity (denoted as 1 and 2 ) are normal. Two specimens (4 and 5) contain both normal and cancer areas. The remaining specimens are diffusely permeated with cancer. These results are typical of our observations of bladder tissues which show that bladder cancer exhibits lower emissivity than normal bladder tissue in the NIR spectral region. The average intensity in the NIR autofluorescence images of the cancer specimens $(3,6-8)$ is lower by a factor of $\approx 0.7$ under 532-nm excitation and $\approx 0.3$ under 632.8-nm compared to that of the normal bladder tissue specimens ( 1 and 2$)$. In addition, the cancer areas are also visible with lower image intensity by a factor of $\approx 0.2$ compared to the normal tissue in the cross-polarized light scattering images. Overall, the experimental 
results regarding the difference in intensity between normal and cancer tissue components can be summarized as shown in table 1:
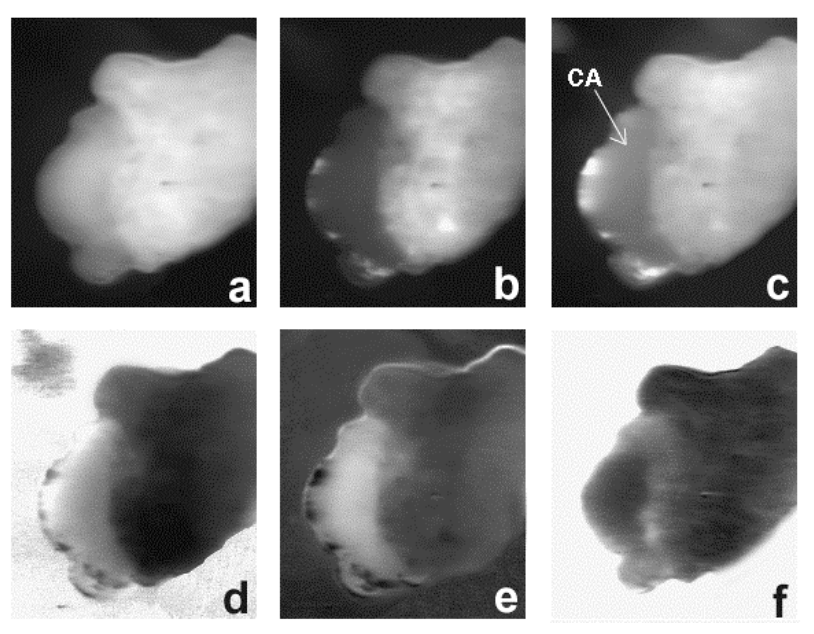

Figure 2: Images of a human bladder tissue specimen . a) Cross polarized light scattering under 700-nm illumination. NIR fluorescence images under 532-nm (b) and 633-nm (c) laser excitation. d) Ratio of the autofluorescence image under 633-nm

Figure 3: The NIR auto-fluorescence image of bladder specimens containing normal and cancer tissue.

\begin{tabular}{|l|l|}
\hline Type of imaging & Average Intensity Difference \\
\hline Cross-polarized light scattering image: & $\Delta \mathrm{I}_{\text {cancer }} \approx(-) 0.10-0.25 \mathrm{I}_{\text {normal }}$ \\
\hline $\begin{array}{l}\text { NIR autofluorescence under 532-nm } \\
\text { excitation: }\end{array}$ & $\Delta \mathrm{I}_{\text {cancer }} \approx(-) 0.30-0.65 \mathrm{I}_{\text {normal }}$ \\
\hline $\begin{array}{l}\text { NIR autofluorescence under 633-nm } \\
\text { excitation: }\end{array}$ & $\Delta \mathrm{I}_{\text {cancer }} \approx(-) 0.25-0.40 \mathrm{I}_{\text {normal }}$ \\
\hline
\end{tabular}

Table 1: Values of average digitized intensities of images containing normal and cancer tissue components.

\section{DISCUSSION}

The techniques discussed above provide imaging of cancer located on the surface or near the surface. The imaging depth of the autofluorescence images is of the order of $1 \mathrm{~mm}$ while the light scattering images may be able to probe slightly deeper into the tissue. However, the persence of an $\approx 20 \%$ diffrence between nornal and cancer tissues in the intensity of the cross-polarized light scattering under NIR ilumination open the possibility to implement the Spectral and Polarization Difference Imaging method (discussed in refs. 8-10). This methods can provide imaging much deeper into the tissue, on the order of 0.5 to $1-\mathrm{cm}$. 
The above results suggest that NIR autofluorescence under long-wavelength excitation in combination with crosspolarized light scattering may be a promising approach to detect and image in real-time cancer in the bladder. The flawless correlation between optical imaging examination and the histological findings suggests that transferring this technology from the pathology room to the cystoscopic suite and then to the urologist's office will be a real advance in the management of patients with and suspected of having bladder cancer. The most common presenting feature of transitional Cell Carcinoma (TCC) of the bladder is hematuria. The tumor is diagnosed at an outpatient cystoscopic examination. The patient is subsequently scheduled for a day- care surgery requiring anesthesia, cystoscopic examination, and transurethral resection (TUR). At present, $75 \%$ of such tumors have not invaded the bladder muscle and are called superficial. Initial therapy consists of a TUR. Tumors undergo histological examination and are given a grade (I, II, III), staged as Ta (confined to mucosa), T1 (into Lamina Propria but muscle below the tumor is uninvolved), or as carcinoma in-situ (CIS) a flat lesion confined to the mucosa which is virtually always high-grade. Fifty percent of this group of superficial tumors will recur following initial therapy. The reasons that TCC tumors recur after resection are most likely the following: 1) bladder tumors are multi-focal lesions by nature and subsequent tumors arise from areas of CIS that are not yet visible, 2) the area of tumor is not fully resected, 3) urothelium is injured during the resection process and seeding by TCC cells occurs, 4) recurrence represents a new tumor development.

Given the above clinical scenario, it is easy to visualize the value of highly sensitive optical detection system in the management of this disease to the patient, doctor, and healthcare system. Such optical detection system would help: 1) define if the tumor was Ta, T1 or T2, 2) define if visibly normal mucosa is in fact harboring CIS, and 3) determine if all the tumor had been resected by close of the case. It could also be beneficial by enhancing the follow-up of patients with Ta and $\mathrm{T} 1$ tumors, could increase the accuracy of detecting recurrent tumors, Ta lesions could be treated in the office rather than the operating room, and discolored areas which can be confused as either CIS or inflammation following intravesical therapy could be accurately analyzed.

\section{ACKNOWLEDGMENTS}

This work was performed in part at UC Lawrence Livermore National Laboratory under the auspices of the U.S. Department of Energy under Contract W-7405-Eng-48 through the Institute for Laser Science and Applications. This research is supported by the California Cancer Research Program.

\section{REFERENCES}

1. Alfano R. R., Tata B., Cordero J., Tomashefsky P., Longo F. W., and Alfano M. A., IEEE J. Quantum Electron., QE-20, 1507-1511 (1984)

2. Huang, D., E. A.Swanson, D. Huang, C. P. Lin, J. S. Schuman, W. G. Stinson, W. Chang, M. R. Hee, T. Flotte, K. Gregory, C. A. Puliafito, J. G. Fujimoto, Science 254, 1991, 1178-1181, 1991.

3. Wang TD, VanDam J, Crawford JM, Preisinger EA, Wang Y, Feld MS, Gastroenterology , 111, 1182-1191 (1996)

4. Ramanujam N, Mitchell MF, MahadevanJansen A, Thomsen SL, Staerkel G, Malpica A, Wright T, Atkinson N, Richards-Kortum R, Photochemistry and Photobiology, 64, 720-735 (1996)

5. Wallace MB, Perelman LT, Backman V, Crawford JM, Fitzmaurice M, Seiler M, Badizadegan K, Shields SJ, Itzkan I, Dasari RR, Van Dam J, Feld MS, Gastroenterology, 119, 677-682 (2000).

6. Alfano R. R., Demos S. G., and Gayen S. K., The Annals of the New York Academy of Sciences, 820, $248-271$ (1997).

7. Sterenborg H.J.C.M., Motamedi M., Wagner R.F., Duvic M., Thomsen S., Jacques S.L., Lasers in Medical Science, 9,191 (1994)

8. Demos S. G. and Alfano R.R., Applied Optics, 36, 150-155, (1997)

9. Demos S. G., Radousky H. B. and Alfano R.R., Optics Express, 7, 23-28, 2000.

10. Demos S. G., Staggs M., Radousky H. B., Electronics Letters, 38, 155-157, 2002 